\title{
Content Management Systems: \\ Trends in Academic Libraries
}

Ruth Sara Connell

\begin{abstract}
Academic libraries, and their parent institutions, are increasingly using Content Management Systems (CMSs) for website management. In this study, the author surveyed academic library web managers from four-year institutions to discover whether they had adopted CMSs, which tools they were using, and their satisfaction with their website management system. Other issues, such as institutional control over library website management, were raised. The survey results showed that CMS satisfaction levels vary by tool and that many libraries do not have input into the selection of their CMS because the determination is made at an institutional level. These findings will be helpful for decision makers involved in the selection of CMSs for academic libraries.
\end{abstract}

\section{INTRODUCTION}

As library websites have evolved over the years, so has their role and complexity. In the beginning, the purpose of most library websites was to convey basic information, such as hours and policies, to library users. As time passed, more and more library products and services became available online, increasing the size and complexity of library websites. Many academic library web designers found that their web authoring tools were no longer adequate for their needs and turned to CMSs to help them manage and maintain their sites.

For other web designers, the choice was not theirs to make. Their institution transitioned to a CMS and required the academic library to follow suit, regardless of whether the library staff had a say in the selection of the CMS or its suitability for the library environment.

The purpose of this study was to examine CMS usage within the academic library market and to provide librarians quantitative and qualitative knowledge to help make decisions when considering switching to, or between, CMSs.

In particular, the objectives of this study were to determine (1) the level of saturation of CMSs in the academic library community; (2) the most popular CMSs within academic libraries, the reasons for the selection of those systems, and satisfaction with those CMSs; (3) if there is a relationship between libraries with their own dedicated Information Technology (IT) staff and those with open source (OS) systems; and (4) if there is a relationship between institutional characteristics and issues surrounding CMS selection.

Ruth Sara Connell (ruth.connell@valpo.edu ) is Associate Professor of Library Services and Electronic Services Librarian, Christopher Center Library Services, Valparaiso University, Valparaiso, IN. 
Although this study largely focuses on CMS adoption and related issues, the library web designers who responded to the survey were asked to identify what method of web management they use if they do not use a CMS and asked about satisfaction with their current system. Thus, information regarding CMS alternatives (such as Adobe's Dreamweaver web content editing software) is also included in the results.

As will be discussed in the literature review, CMSs have been broadly defined in the past. Therefore, for this study participants were informed that only CMSs used to manage their primary public website were of interest. Specifically, CMSs were defined as website management tools through which the appearance and formatting is managed separately from content, so that authors can easily add content regardless of web authoring skills.

\section{LITERATURE REVIEW}

Most of the library literature regarding CMS adoption consists of individual case studies describing selection and implementation at specific institutions. There are very few comprehensive surveys of library websites or the personnel in charge of academic library websites to determine trends in CMS usage.

The published studies including CMS usage within academic libraries do not definitively answer whether overall adoption has increased. In 2005 several Georgia State University librarians surveyed web librarians at sixty-three of their peer institutions, and of the sixteen responses, six (or 38 percent) reported use of "CMS technology to run parts of their web site." ${ }^{1}$ A 2006 study of web managers from wide range of institutions (Associates to Research) indicated a 26 percent (twenty-four of ninety-four) CMS adoption rate. ${ }^{2}$ A more recent 2008 study of institutions of varying sizes resulted in a little more than half of respondents indicating use of CMSs, although the authors note that "people defined CMSs very broadly," 3 including tools like Moodle and CONTENTdm, and some of those libraries indicated they did not use the CMS to manage their website. A 2012 study by Comeaux and Schmetzke differs from the others mentioned here in that they reviewed academic library websites of the fifty-six campuses offering ALA-accredited graduate degrees (generally larger universities) and used tools and examined page code to try to determine on their own if the libraries used CMSs, as opposed to polling librarians at those institutions to ask them to self-identify if they used CMSs. They identified nineteen out of fifty-six (34 percent) sites using CMSs. The authors offer this caveat, "It is very possible that more sites use CMSs than could be readily identified. This is particularly true for 'home-grown' systems, which are unlikely to leave any readily discernible source code." 4 Because of different methodologies and population groups studied in these studies, it is not possible to draw conclusions regarding CMS adoption rates within academic libraries over time using these results.

As mentioned previously, some people define CMSs more broadly than others. One example of a product that can be used as a CMS, but is not necessarily a CMS, is Springshare's LibGuides. Many libraries use LibGuides as a component of their website to create guides. However, some libraries have utilized the product to develop their whole site, in effect using it as a CMS. A case study by 
two librarians at York College describes why they chose LibGuides as their CMS instead of as a more limited guide creation tool. 5

Several themes recurred throughout many of the case study articles. One common theme was the issue of lack of control and problems of collaboration between academic libraries and the campus entities controlling website management. Amy York, the web services librarian at Middle

Tennessee State University, described the decision to transition to a CMS in this way, "And while it was feasible for us to remain outside of the campus CMS and yet conform to the campus template, the head of the IT web unit was quite adamant that we move into the CMS." 6 In a study by Bundza et al., several participants who indicated dissatisfaction with website maintenance mentioned "authority and decision-making issues" as well as "turf struggles." 7

Other articles expressed more positive collaborative experiences. Morehead State University librarians Kmetz and Bailey noted, "When attending conferences and hearing the stories of other libraries, it became apparent that a typical relationship between librarians and a campus IT staff is often much less communicative and much less positive than [ours]. Because of the relatively smooth collaborative spirit, a librarian was invited in 2003 to participate in the selection of a CMS system." ${ }^{8}$ Kimberley Stephenson also emphasized the advantageous relationships that can develop when a positive approach is used, "Rather than simply complaining that staff from other departments do not understand library needs, librarians should respectfully acknowledge that campus Web developers want to create a site that attracts users and consider how an attractive site that reflects the university's brand can be beneficial in promoting library resources and services." ${ }^{9}$ However, earlier in the article she does acknowledge that the iterative and collaborative process between the library and their University Relations (UR) department was occasionally contentious and that the web services librarian notifies UR staff before making changes to the library homepage. 10

Another common theme in the literature was the reasoning behind transitioning to a CMS. One commonly cited criterion was access control or workflow management, which allows site administrators to assign contributors editorial control over different sections of the site or approve changes before publishing. ${ }^{11}$ However, although this feature is considered a requirement by many libraries, it has its detractors. Kmetz and Bailey indicated that at Morehead State University, "approval chains have been viewed as somewhat stifling and potentially draconian, so they have not been activated." 12

These studies greatly informed the questions used and development of the survey instrument for this study.

\section{METHOD}

In designing the survey instrument, questions were considered based on how they informed the objectives of the study. To simplify analysis, it was important to compile as comprehensive a list of 
CMSs as possible. This list was created by pulling CMS names from the literature review, the Web4Lib discussion list, and the CMSmatrix website (www.cmsmatrix.org).

In order to select institutions for distribution, the 2010 Carnegie Classification of Institutions of Higher Education basic classification lists were used. ${ }^{13}$ The author chose to focus on three broad classifications:

1. Research institutions consisting of the following Carnegie basic classifications: Research Universities (very high research activity), Research Universities (high research activity), and DRU: Doctoral/Research Universities.

2. Master's institutions consisting of the following Carnegie basic classifications: Master's Colleges and Universities (larger programs), Master's Colleges and Universities (medium programs), Master's Colleges and Universities (smaller programs).

3. Baccalaureate institutions consisting of the following Carnegie basic classifications: Baccalaureate Colleges-Arts \& Sciences and Baccalaureate Colleges-Diverse Fields.

The basic classification lists were downloaded into Excel with each of the three categories in a different worksheet, and then each institution was assigned a number using the random number generator feature within Excel. The institutions were then sorted by those numbers creating a randomly ordered list within each classification.

To determine sample size for a stratified random sampling, Ronald Powell's "Table for Determining Sample Size from a given population"14 (with a .05 degree of accuracy) was used. Each classification's population was considered separately, and the appropriate sample size chosen from the table. The population size of each of the groups (total number of institutions within that Carnegie classification) and the corresponding sample sizes were

- $\quad$ research: population $=297$, sample size $=165$;

- $\quad$ master's: population $=727$, sample size $=248$;

- baccalaureate: population $=662$, sample size $=242$.

The total number of institutions included in the sample size was 655.

The author then went through the list of selected institutions and searched online to find their library webpages and find the person most likely responsible for the library's website. During this process, there were some institutions, mostly for-profits, for which a library website could not be found. When this occurred, that institution was eliminated and the next institution on the list used in its place. In some cases, the person responsible for web content was not easily identifiable; in these cases an educated guess was made when possible, or else the director or a general library email address was used.

The survey was made available online and distributed via e-mail to the 655 recipients on October 1,2012 . Reminders were sent on October 10 and October 18 , and the survey was closed on October 26, 2012. Out of 655 recipients, 286 responses were received. Some of those responses 
had to be eliminated for various reasons. If two responses were received from one institution, the more complete response was used while the other response was discarded. Some responses included only an answer to the first question (name of institution or declination of that question to answer demographic questions) and no other responses; these were also eliminated. Once the invalid responses were removed, 265 remained, for a 40 percent response rate.

Before conducting an analysis of the data, some cleanup and standardization of results was required. For example, a handful of respondents indicated they used a CMS and then indicated that their CMS was Dreamweaver or Adobe Contribute. These responses were recoded as non-CMS responses. Likewise, one respondent self-identified as a non-CMS user but then listed Drupal as his/her web management tool and this was recoded as a CMS response.

\section{Demographic Profile of Respondents}

For the purposes of gathering demographic data, respondents were offered two options. They could provide their institution's name, which would be used solely to pair their responses with the appropriate Carnegie demographic categories (not to identify them or their institution), or they could choose to answer a separate set of questions regarding their size, public/private affiliation, and basic Carnegie classification.

The basic Carnegie classification of the largest response group was master's with 102 responses (38 percent); then baccalaureate institutions ( 94 responses or 35 percent), and then Research institutions (69 responses or 26 percent). This correlates pretty closely with the distribution percentages, which were 38 percent master's ( 248 out of 655 ), 37 percent baccalaureate ( 242 out of 655), and 25percent research (165 out of 655).

Of the 265 responses, 95 (36 percent) came from academic librarians representing public institutions and 170 (64 percent) from private. Of the private institutions, the vast majority (166 responses or 98 percent) were not-for-profit, while 4 ( 2 percent) were for-profits.

To define size, the Carnegie size and setting classification was used. Very small institutions are defined as less than 1,000 full-time equivalent (FTE) enrollment, small is 1,000-2,999 FTE, medium is 3,000-9,999 FTE, and large is at least 10,000 FTE. The largest group of responses came from small institutions ( 105 responses or 40 percent), then medium (67 responses or 25 percent), large (60 responses or 23 percent), and very small (33 responses or 12 percent).

\section{RESULTS}

The first question asking for institutional identification (or alternative routing to Carnegie classification questions) was the only question for which an answer was required. In addition, because of question logic, some people saw questions that others did not based on how they answered previous questions. Thus, the number of responses varies for each question.

One of the objectives of this study was to identify if there were traits among institutional characteristics and CMS selection and management. The results that follow include both 
descriptive statistics and statistically significant inferential statistics discovered using Chi-square and Fisher's exact tests. Statistically significant results are labeled as such.

The responses to this survey show that most academic libraries are using a CMS to manage their main library website (169out of 265 responses or 64 percent). Overall, CMS users expressed similar (although slightly greater) satisfaction levels with their method of web management (see table 1.)

\begin{tabular}{|c|c|c|c|}
\hline \multicolumn{4}{|c|}{$\begin{array}{c}\text { Table } 1 \\
\text { Satisfaction by CMS Use }\end{array}$} \\
\hline & & \multicolumn{2}{|c|}{ Use a CMS to manage library website } \\
\hline & & Yes & No \\
\hline \multirow{2}{*}{$\begin{array}{l}\text { User is highly } \\
\text { satisfied or satisfied }\end{array}$} & Yes & 79 responses or $54 \%$ & 41 responses or $47 \%$ \\
\hline & No & 68 responses or $46 \%$ & 46 responses or $53 \%$ \\
\hline \multicolumn{2}{|l|}{ Total } & 147 responses or $100 \%$ & 87 responses or $100 \%$ \\
\hline
\end{tabular}

\section{Non-CMS Users}

Non-CMS users were asked what software or system they use to govern their site. By far, the most popular system mentioned among the 82 responses was Adobe Dreamweaver, with 24 (29 percent) users listing it as their only or primary system. Some people listed Dreamweaver as part of a list of tools used; for example "PHP / MySQL, Integrated Development Environments (php storm, coda), Dreamweaver, etc.," and if all mentions of Dreamweaver are included, the number of users rises to 31 (38 percent). Some version of "hand coded" was the second most popular answer with 9 responses (11 percent), followed by Adobe Contribute with 7 ( 9 percent). Many of the "other" responses were hard to classify and were excluded from analysis. Some examples include:

- $\quad$ FTP to the web

- Voyager Public Web Browser ezProxy

- Excel, e-mail, file folders on shared drives

Among the top three non-CMS web management systems, Dreamweaver users were most satisfied, selecting highly satisfied or satisfied in 15 out of 24 (63 percent) cases. Hand coders were highly satisfied or satisfied in 5out of 9 of cases (56 percent), and Adobe Contribute users were only highly satisfied or satisfied in 3 out of 7 (43 percent) cases.

Respondents not using a CMS were asked whether they were considering a move to a CMS within the next two years. Most (59 percent) said yes. Research libraries were much more likely to be planning such a move (81percent) than master's (50 percent) or baccalaureate (45 percent) libraries (see table 2.) A Chi-square test rejects the null hypothesis that the consideration of a move to CMS is independent of basic Carnegie classification; this difference was significant at the $p$ $=0.038$ level. 


\begin{tabular}{|c|c|c|c|c|}
\hline & $\begin{array}{r}\text { Jsers Consideri } \\
\text { by }\end{array}$ & $\begin{array}{r}\text { Table } 2 \\
\text { ig a Move to a } \\
\text { Carnegie Class }\end{array}$ & $\begin{array}{l}\text { within the } \mathrm{N} \\
\text { tion* }\end{array}$ & wo Years \\
\hline & Baccalaureate & Master's & Research & Total \\
\hline No & $\begin{array}{l}11 \text { responses } \\
\text { or } 55 \%\end{array}$ & $\begin{array}{l}11 \text { responses } \\
\text { or } 50 \%\end{array}$ & $\begin{array}{l}4 \text { responses } \\
\text { or } 19 \%\end{array}$ & $\begin{array}{l}26 \text { responses } \\
\text { or } 41 \%\end{array}$ \\
\hline Yes & $\begin{array}{l}9 \text { responses or } \\
45 \%\end{array}$ & $\begin{array}{l}11 \text { responses } \\
\text { or } 50 \%\end{array}$ & $\begin{array}{l}17 \text { responses } \\
\text { or } 81 \%\end{array}$ & $\begin{array}{l}37 \text { responses } \\
\text { or } 59 \%\end{array}$ \\
\hline Total & $\begin{array}{l}20 \text { responses } \\
\text { or } 100 \%\end{array}$ & $\begin{array}{l}22 \text { responses } \\
\text { or } 100 \%\end{array}$ & $\begin{array}{l}21 \text { responses } \\
\text { or } 100 \%\end{array}$ & $\begin{array}{l}63 \text { responses } \\
\text { or } 100 \%\end{array}$ \\
\hline \multicolumn{5}{|c|}{ Chi-square $=6.526, \mathrm{df}=2, \mathrm{p}=.038$} \\
\hline
\end{tabular}

Non-CMS users were asked to provide comments related to topics covered in the survey, and here is a sampling of responses received:

- CMSs cost money that our college cannot count on being available on a yearly basis.

- The library doesn't have overall responsibility for the website. University web services manages the entire site, I submit changes to them for inclusion and updates.

- We are so small that the time to learn and implement a CMS hardly seems worth it. So far this low-tech method has worked for us.

- The main university site was moved to a CMS in 2008. The library was not included in that move because of the number of pages. I hear rumors that we will be forced into the CMS that is under consideration for adoption now. The library has had zero input in the selection of the new CMS.

\section{CMS Users}

When respondents indicated their library used a CMS, they were routed to a series of CMS related questions. The first question asked which CMS their library was using. Of the 153 responses, the most popular CMSs were Drupal (40); WordPress (15); LibGuides (14), which was defined within the survey as a CMS "for main library website, not just for guides"; Cascade Server (12); Ektron (6); and ModX and Plone (5 each).

These users were also asked about their overall satisfaction with their systems. Among the top four CMSs, LibGuides users were the most satisfied, selecting highly satisfied or satisfied in 12 out of 12 (100 percent) cases. The remaining three systems' satisfaction ratings (highly satisfied or satisfied) were as follows: WordPress (12out of 15 cases or 80 percent), Drupal (26out of 38 cases or 68 percent), and Cascade Server ( 3 out of 11 cases or 27 percent).

When asked whether they would switch systems if given the opportunity, most (61 out of 109 cases or 56 percent) said no. Looking at the responses for the top four CMSs, responses echo the 
satisfaction responses. LibGuides users were least likely to want to switch ( 0 out of 7 cases or 0 percent), followed by Wordpress ( 1 out of 5 cases or 17 percent), Drupal (8out of 23 cases or 26 percent), and Cascade Server (3 out of 7 or 43 percent) users.

Respondents were asked whether their library uses the same CMS as their parent institution. Most (106 out of 169 cases or 63 percent) said yes. Libraries at large institutions (over 10,000 FTE) were much less likely (34 percent) than their smaller counterparts to share a CMS with their parent institution (see table 3.) A Chi-square test rejects the null hypothesis that sharing a CMS with a parent institution is independent of size: at a significance level of $p=0.001$, libraries at smaller institutions are more likely to share a CMS with their parent.

\begin{tabular}{|l|l|l|l|l|l|}
\hline \multicolumn{5}{|c|}{ Table 3 } \\
CMS Users Whose Libraries Use the Same CMS as their Parent Institution by Size \\
\hline & Large & Medium & Small & Very Small & Total \\
\hline No & $\begin{array}{l}23 \text { responses } \\
(66 \%)\end{array}$ & $\begin{array}{l}15 \text { responses } \\
(33 \%)\end{array}$ & $\begin{array}{l}19 \text { responses } \\
(27 \%)\end{array}$ & $\begin{array}{l}6 \text { responses } \\
(35 \%)\end{array}$ & $\begin{array}{l}63 \text { responses } \\
(37 \%)\end{array}$ \\
\hline Yes & $\begin{array}{l}12 \text { responses } \\
(34 \%)\end{array}$ & $\begin{array}{l}31 \text { responses } \\
(67 \%)\end{array}$ & $\begin{array}{l}52 \text { responses } \\
(73 \%)\end{array}$ & $\begin{array}{l}11 \text { responses } \\
(65 \%)\end{array}$ & $\begin{array}{l}106 \text { responses } \\
(63 \%)\end{array}$ \\
\hline Total & $\begin{array}{l}35 \text { responses } \\
(100 \%)\end{array}$ & $\begin{array}{l}46 \text { responses } \\
(100 \%)\end{array}$ & $\begin{array}{l}71 \text { responses } \\
(100 \%)\end{array}$ & $\begin{array}{l}17 \text { responses } \\
(100 \%)\end{array}$ & $\begin{array}{l}169 \text { responses } \\
(100 \%)\end{array}$ \\
\hline \multicolumn{4}{|l|}{ Chi-square $=15.921, \mathrm{df}=3, \mathrm{p}=.001$} & & \\
\hline
\end{tabular}

Not surprisingly, a similar correlation holds true for comparing shared CMSs and simplified basic Carnegie classification. Baccalaureate and Master's libraries were more likely to share CMSs with their institutions (69 percent and 71 percent respectively) than Research libraries (42 percent) (see table 4.) At a significance level of $p=0.004$, a Chi-square test rejects the null hypothesis that sharing a CMS with a parent institution is independent of basic Carnegie classification.

\begin{tabular}{|l|l|l|l|l|}
\hline \multicolumn{5}{|c|}{ Table 4 } \\
\hline \multicolumn{5}{|c|}{$\begin{array}{l}\text { CMS Users Whose Libraries Use the Same CMS as their Parent Institution, } \\
\text { by Carnegie Classification }\end{array}$} \\
\hline No & Baccalaureate & Master's & Research & Total \\
& $\begin{array}{l}19 \text { responses } \\
(31 \%)\end{array}$ & $\begin{array}{l}18 \text { responses } \\
(29 \%)\end{array}$ & $\begin{array}{l}26 \text { responses } \\
(58 \%)\end{array}$ & $\begin{array}{l}63 \text { responses } \\
(37 \%)\end{array}$ \\
\hline Yes & $\begin{array}{l}43 \text { responses } \\
(69 \%)\end{array}$ & $\begin{array}{l}44 \text { responses } \\
(71 \%)\end{array}$ & $\begin{array}{l}19 \text { responses } \\
(42 \%)\end{array}$ & $\begin{array}{l}106 \text { responses } \\
(63 \%)\end{array}$ \\
\hline Total & $\begin{array}{l}62 \text { responses } \\
(100 \%)\end{array}$ & $\begin{array}{l}62 \text { responses } \\
(100 \%)\end{array}$ & $\begin{array}{l}45 \text { responses } \\
(100 \%)\end{array}$ & $\begin{array}{l}169 \text { responses } \\
(100 \%)\end{array}$ \\
\hline Chi-square $=11.057, \mathrm{df}=2, \mathrm{p}=.004$ & \\
\hline
\end{tabular}


When participants responded that their library shared a CMS with the parent institution, they were asked a follow up question about whether the library made the transition with the parent institution. Most (80 out of 99 cases or 81 percent) said yes, the transition was made together. However, private institutions were more likely to have made the switch together (88 percent) than public (63 percent) (See table 5.) A Fisher's exact test rejects the null hypothesis that transition to CMS is independent of institutional control: at a significance level of $p=0.010$, private institutions are more likely than public to move to a CMS in concert.

\begin{tabular}{|l|l|l|}
\hline \multicolumn{3}{|c|}{ Users Whose Libraries and Parent Institutions Use the Same CMS: } \\
Transition by Public/Private Control*
\end{tabular}

Similarly, a relationship existed between transition to CMS and basic Carnegie classification.

Baccalaureate institutions (93 percent) were more likely than Master's (80 percent), which were more likely than Research institutions (53 percent) to make the transition together (see table 6.) A Chi-square test rejects the null hypothesis that the transition to CMS is independent of basic Carnegie classification: at a significance level of $p=0.002$, higher degree granting institutions are less likely to make the transition together.

\begin{tabular}{|c|c|c|c|c|}
\hline Users & $\begin{array}{r}\text { hose Libraries } \\
\text { Transit }\end{array}$ & $\begin{array}{r}\text { Table } 6 \\
\text { and Parent In } \\
\text { on by Carnegi }\end{array}$ & $\begin{array}{l}\text { tions Use the } \\
\text { assification* }\end{array}$ & e CMS: \\
\hline & Baccalaureate & Master's & Research & Total \\
\hline $\begin{array}{l}\text { Switched } \\
\text { Independently }\end{array}$ & $\begin{array}{l}3 \text { responses } \\
(7 \%)\end{array}$ & $\begin{array}{l}8 \text { responses } \\
(21 \%)\end{array}$ & $\begin{array}{l}8 \text { responses } \\
(47 \%)\end{array}$ & $\begin{array}{l}19 \text { responses } \\
(19 \%)\end{array}$ \\
\hline $\begin{array}{l}\text { Switched } \\
\text { Together }\end{array}$ & $\begin{array}{l}40 \text { responses } \\
(93 \%)\end{array}$ & $\begin{array}{l}31 \text { responses } \\
(80 \%)\end{array}$ & $\begin{array}{l}9 \text { responses } \\
(53 \%)\end{array}$ & $\begin{array}{l}80 \text { responses } \\
(81 \%)\end{array}$ \\
\hline Total & $\begin{array}{l}43 \text { responses } \\
(100 \%)\end{array}$ & $\begin{array}{l}39 \text { responses } \\
(101 \%)^{* *}\end{array}$ & $\begin{array}{l}17 \text { responses } \\
(100 \%)\end{array}$ & $\begin{array}{l}99 \text { responses } \\
(100 \%)\end{array}$ \\
\hline \multicolumn{5}{|c|}{$\begin{array}{l}\text { Chi-square }=12.693, \mathrm{df}=2, \mathrm{p}=.002 \\
* \text { Excludes responses where people indicated "other" } \\
* * \text { Due to rounding, total is greater than } 100 \%\end{array}$} \\
\hline
\end{tabular}


This study indicates that for libraries that transitioned to a CMS with their parent institution, the transition was usually forced. Out of the 88 libraries that transitioned together and indicated whether they were given a choice, only 8 libraries (9 percent) had a say in whether to make that transition. And even though academic libraries were usually forced to transition with their institution, they did not usually have representation on campus-wide CMS selection committees. Only 25 percent (22 out of 87 ) respondents indicated that their library had a seat at the table during CMS selection.

When comparing CMS satisfaction ratings among libraries that were represented on CMS selection committees versus those that had no representation, it is not surprising that those with representation were more satisfied (13 out of 22 cases or 59 percent) than those without (21 out of 59 cases or 36 percent). The same holds true for those libraries given a choice whether to transition. Those given a choice were satisfied more often (6out of 8 cases or 75 percent) than those forced to transition ( 21 out of 71 cases or 30 percent).

Respondents who said that they were not on the same CMS as their institution were asked why they chose a different system. Many of the responses indicated a desire for freedom from the controlling influence of either IT and marketing arms of the institution :

- We felt Drupal offered more flexibility for our needs than Cascade, which is what the University at large was using. I've heard more recently that the University may be considering switching to Drupal.

- University PR controls all aspects of the university CMS. We want more freedom.

- We are a service-oriented organization, as opposed to a marketing arm. We by necessity need to be different.

CMS users were asked to provide a list of three factors most important in their selection of their CMS and to rank their list in order of importance. The author standardized the responses, e.g. "price" was recorded as "cost." The factors listed first, in order of frequency, were ease of use (15), flexibility (10), and cost (6). Ignoring the ranking, 38 respondents listed ease of use somewhere in their "top three", while 23 listed cost, and 16 listed flexibility.

Another objective of this study was to determine if there was a positive correlation between libraries with their own dedicated IT staff and those who chose open source CMSs. Therefore CMS users were asked if their library had its own dedicated IT staff, and 66 out of 143 libraries (46 percent) said yes. Then the CMSs used by respondents were translated into two categories, open source or proprietary systems (when a CMS listed was unknown it was coded as a missing value), and a Fisher's exact test was run against all cases that had values for both variables to see if a correlation existed. Although those with library IT had open source systems more frequently than those without, the difference was not significant (see table 7.) 


\begin{tabular}{|l|l|l|l|l|}
\hline \multicolumn{5}{|c|}{ Table 7 } \\
\hline & \multicolumn{4}{|c|}{ Libraries with own personnel by Open Source CMSs } \\
\hline & & Yes & No & Total \\
\hline CMS is Open & Yes & $\begin{array}{l}37 \text { responses } \\
(73 \%)\end{array}$ & $\begin{array}{l}32 \text { responses } \\
(57 \%)\end{array}$ & $\begin{array}{l}69 \text { responses } \\
(65 \%)\end{array}$ \\
\cline { 2 - 5 } & No & $\begin{array}{l}\text { 14 responses } \\
(28 \%)\end{array}$ & $\begin{array}{l}24 \text { responses } \\
(43 \%)\end{array}$ & $\begin{array}{l}38 \text { responses } \\
(36 \%)\end{array}$ \\
\hline & $\begin{array}{l}51 \text { responses } \\
(101 \%)^{*}\end{array}$ & $\begin{array}{l}56 \text { responses or } \\
(100 \%)\end{array}$ & $\begin{array}{l}107 \text { responses } \\
(101 \%)^{*}\end{array}$ \\
\hline
\end{tabular}

In another question, people were asked to self-identify if their organization uses an open source CMS, and if so asked whether they have outsourced any of its implementation or design to an outside vendor. Most (61 out of 77 cases or 79 percent) said they had not outsourced implementation or design. One person commented, "No, I don't recommend doing this. The cost is great, you lose the expertise once the consultant leaves, and the maintenance cost goes through the roof. Hire someone fulltime or move a current position to be the keeper of the system."

One of the advantages of having a CMS is the ability to give multiple people, regardless of their web authoring skills, the opportunity to edit webpages. Therefore, CMS users were asked how many web content creators they have within their library. Out of 152 responses, the most frequent range cited was 2-5 authors ( 72 responses or 47 percent), followed by (33 responses or 22 percent) with only one author, 6-10 authors (20 responses or 13 percent), 21-50 authors (16 responses or 11 percent), 11-20 authors ( 6 responses or 4 percent), and over 50 authors ( 5 responses or 3 percent). Because this question was an open ended response and responses varied greatly, including "Over 100 (over 20 are regular contributors)" and "1-3", standardization was required. When a range or multiple numbers were provided, the largest number was used.

Respondents were asked whether their library uses a workflow management process requiring page authors to receive approval before publishing content. Of the 131 people who responded yes or no, most (88 responses or 67 percent) said no.

CMS users were asked to provide comments related to topics covered in the survey. Many comments mentioned issues of control (or lack thereof), while another common theme was concerns with specific CMSs. Here is a sampling of responses received:

- Having dedicated staff is a necessity. There was a time when these tools could be installed and used by a techie generalist. Those days are over. A professional content person and a professional CMS person are a must if you want your site to look like a professional site... 
I'm shocked at how many libraries switched to a CMS yet still have a site that looks and feels like it was created 10 years ago.

- Since the CMS was bred in-house by another university department, we do not have control over changing the design or layout. The last time I requested a change, they wanted to charge us.

- Our university marketing department, which includes the web team, is currently in the process of switching [CMSs]. We were not invited to be involved in the selection process for a new CMS, although they did receive my unsolicited advice.

- We compared costs for open source and licensed systems, and we found the costs to be approximately equivalent based on the development work we would have needed in an Open Source environment.

- The library was not part of the original selection process for the campus' first CMS because my position didn't exist at that time. Now that we have a dedicated web services position, the library is considered a "power user" in the CMS and we are often part of the campus wide discussions about the new CMS and strategic planning involving the campus website.

- We currently do not have the preferred level of control over our library website; we fought for customization rights for our front page, and won on that front. However, departments on campus do not have permission to install or configure modules, which we hope will change in the future.

- There's a huge disconnect between IT /administration and the library regarding unique needs of the library in the context of web-based delivery of information.

\section{DISCUSSION}

Comparing the results of this study to previous studies indicates that CMS usage within academic libraries is rising. The 64 percent CMS adoption rate found in this survey, which used a more narrow definition of CMS than some previous studies cited in the literature review, is higher than adoption rates in any of said studies. As more libraries make the transition, it is important to know how different CMSs have been received among their peers.

Although CMS users are slightly more satisfied than non-CMS users (54 percent vs. 47 percent), the tools used matter. So if a library using Dreamweaver to manage their site is given an option of moving with their institution to a CMS and that CMS is Cascade Server, they should strongly consider sticking with their current non-CMS method based on the respective satisfaction levels reported in this study (63 percent vs. 27 percent).

Satisfaction levels are important, but should not be considered in a vacuum. For example, although LibGuides users reported very high satisfaction levels (100 percent were satisfied or very satisfied), users were mostly (11 out of 14 users or 79 percent) small or very small schools, while the remaining three (21percent) were medium schools. No large schools reported using LibGuides as their CMS. LibGuides may be wonderful for a smaller school without need of much 
customization or, in some cases, access to technical expertise but may not be a good CMS solution for larger institutions.

One of the largest issues raised by survey respondents was libraries' control, or lack thereof, when moving to a campus-selected CMS. Given the complexity of academic libraries websites, library representation on campus-wide CMS selection committees is warranted. Not only are libraries more satisfied with the results when given a say in the selection, but libraries have special needs when it comes to website design that other campus units do not. Including library representation ensures those needs are met.

Some of the respondents' comments regarding lack of control over their sites are disturbing to libraries being forced or considering a move to a campus CMS. Clearly, having to pay another campus department to make changes to the library site is not an attractive option for most libraries. Nor should libraries have to fight for the right or ability to customize their home pages. Developing good working relationships with the decision makers may help prevent some of these problems, but likely not all. This study indicates that it is not uncommon for academic libraries to be forced into CMSs, regardless of the CMSs acceptability to the library environment.

\section{CONCLUSION}

The adoption of CMSs to manage academic libraries' websites is increasing, but not all CMSs are created equal. When given input into switching website management tools, library staff have many factors to take into consideration. These include, but are not limited to, in-house technical expertise, desirability of open source solutions, satisfaction of peer libraries with considered systems, and library specific needs, such as workflow management and customization requirements.

Ideally, libraries would always be partners at the table when campus-wide CMS decisions are being made, but this study shows that this does not happen in most cases. If a library suspects that it is likely to be required to move to a campus-selected system, its staff should be alert for news of impending changes so that they can work to be involved at the beginning of the process to be able to provide input. A transition to a bad CMS can have long-term negative effects on the library, its users, and staff. A library's website is its virtual "branch" and vitally important to the functioning of the library. The management of such an important component of the library should not be left to chance.

\section{REFERENCES}

1. Doug Goans, Guy Leach, and Teri M. Vogel, "Beyond HTML: Developing and Re-imagining Library Web Guides in a Content Management System," Library Hi Tech 24, no. 1 (2006): 29-53, doi:10.1108/07378830610652095.

2. Ruth Sara Connell, "Survey of Web Developers in Academic Libraries," The Journal of Academic Librarianship 34, no. 2 (March 2008): 121-129, doi:10.1016/j.acalib.2007.12.005. 
3. Maira Bundza, Patricia Fravel Vander Meer, and Maria A. Perez-Stable, "Work of the Web Weavers: Web Development in Academic Libraries," Journal of Web Librarianship 3, no. 3 (July 2009): 239-62.

4. David Comeaux and Axel Schmetzke, "Accessibility of Academic Library Web Sites in North America-Current Status and Trends (2002-2012)." Library Hi Tech 31, no. 1 (January 28, 2013): 2 .

5. Daniel Verbit and Vickie L. Kline, “Libguides: A CMS for Busy Librarians," Computers in Libraries 31, no. 6 (July 2011): 21-25.

6. Amy York, Holly Hebert, and J. Michael Lindsay, "Transforming the Library Website: You and the IT Crowd," Tennessee Libraries 62, no. 3 (2012).

7. Bundza, Vender Meer, and Perez-Stable, "Work of the Web Weavers: Web Development in Academic Libraries."

8. Tom Kmetz and Ray Bailey, "Migrating a Library's Web Site to a Commercial CMS Within a Campus-wide Implementation," Library Hi Tech 24, no. 1 (2006): 102-14, doi:10.1108/07378830610652130.

9. Kimberley Stephenson, "Sharing Control, Embracing Collaboration: Cross-Campus Partnerships for Library Website Design and Management," Journal of Electronic Resources Librarianship 24, no. 2 (April 2012): 91-100.

10. Ibid.

11. Elizabeth L. Black, "Selecting a Web Content Management System for an Academic Library Website," Information Technology \& Libraries 30, no. 4 (December 2011): 185-89; Andy Austin and Christopher Harris, "Welcome to a New Paradigm," Library Technology Reports 44, no. 4 (June 2008): 5-7; Holly Yu , "Chapter 1: Library Web Content Management: Needs and Challenges," in Content and Workflow Management for Library Web Sites: Case Studies, ed. Holly Yu (Hersey, PA: Information Science Publishing, 2005), 1-21; Wayne Powel and Chris Gill, "Web Content Management Systems in Higher Education," Educause Quarterly 26, no. 2 (2003): 4350; Goans, Leach, and Vogel, "Beyond HTML."

12. Kmetz and Bailey, "Migrating a Library’s Web Site."

13. Carnegie Foundation for the Advancement of Teaching, 2010 Classification of Institutions of Higher Education, accessed February 4, 2013, http://classifications.carnegiefoundation.org/descriptions/basic.php.

14. Ronald R. Powell , Basic Research Methods for Librarians (Greenwood, 1997). 